Check for updates

Portsmouth Hospitals NHS Trust

drparthakar@gmail.com Follow Partha on Twitter: @parthaskar Cite this as: BMJ 2020;371:m3931 http://dx.doi.org/10.1136/bmj.m3931 Published: 13 October 2020

\section{THE BOTTOM LINE}

\section{Partha Kar: We must be honest with patients about the future of services}

\section{Partha Kar consultant in diabetes and endocrinology}

There's a commonly held public assumption that the NHS can provide everything medical science has to offer, to all who need it-or, at least, that this is the stated aim. Yet prioritisation has always existed in healthcare, whether driven by policy or the embedding of the "inverse care law." It's just that, as a system, the NHS has rarely been able to acknowledge this publicly.

Political rhetoric around the NHS from all parties may mean that healthcare leaders have balked at the idea that prioritisation of services can be openly discussed. As a result, the NHS finds itself caught between its public perception as the country's "jewel in the crown"-offering all available treatments to everyone-and the political imperative for it to function within a given funding envelope. But covid-19 has brought many an issue starkly to the fore.

Another uncomfortable truth is how much the NHS actually "engages with users” or is "patient centred." How many times have we been brave enough to say that funding constraints and other restrictions mean that we just can't be as patient centred as we'd like? The belief that we can give everything to everyone combines with another idea - that the NHS is staffed by tireless workers and "angels"-to form a toxic cocktail. This creates its own rhetoric, leading to dedicated professionals doing "that bit extra" beyond their designated hours and job plan. At some point, "that bit extra” takes its toll on the individual. However much we desire to help, all humans have their limit-risking burnout or the overarching impact on family life.

As the NHS looks to life beyond covid-19 and is forced to play catch-up, we find ourselves at an interesting juncture. Whether it be surgery, cancer care, or routine reviews for chronic conditions, something may have to give. If we were in a tricky situation before, the pandemic has added a new urgency: with no obvious end to restrictions on the horizon, we're entering an era of prioritisation. And it's not as though throwing money at the problem would solve it-the issue is actually having the staff to do the catching up while running business as usual, within the restrictions of the pandemic response.

Prioritisation may well be the order of the day, and we'll need patient organisations to be on our side as never before, to help us manage expectations and deliver on the chosen priorities. Will some miss out or have to wait longer, behind others? In all probability, yes. Denying this shows a lack of insight, a blinkered view of NHS capacity, or a degree of faith that does no one any favours.

This conversation won't be easy, but we need to work with the patient community to manage expectations-or the false rhetoric of a "closed NHS," and recent unfair finger pointing at primary care, will continue to take a hold. I think it's a false belief that the wider community isn't mature enough to have that discussion, but it leaves healthcare leaders to make their own judgments on engagement.

In these unprecedented times, we need to be honest and clear about what's feasible within existing staffing and funding envelopes. To suggest that all will be OK isn't fair to the staff or the people.

Competing interests: www.bmj.com/about-bmj/freelance-contributors.

Provenance and peer review: Commissioned; not externally peer reviewed. 